\title{
Impact of Lithium Composition on Structural, Electronic and Optical Properties of Lithium Cobaltite Prepared by Solid-state Reaction
}

\author{
F. Khatun ${ }^{\mathrm{a}}$, M. A. Gafur ${ }^{\mathrm{b}}$, M. S. Ali ${ }^{\mathrm{a}}$, M. S. Islam ${ }^{\mathrm{a}}$, and M. A. R. Sarker, ${ }^{\mathrm{a}, *}$ \\ ${ }^{a}$ Department of Physics, Rajshahi University, Rajshahi-6205, Bangladesh \\ ${ }^{\mathrm{b}}$ Bangladesh Council for Scientific and Industrial Research (BCSIR), Kudrat-I-Khuda Road, \\ Dhanmondi, Dhaka-1205, Bangladesh
}

Received 6 February 2014, accepted in final revised form 24 April 2014

\begin{abstract}
The lithium-cobalt oxide $\mathrm{Li}_{x} \mathrm{CoO}_{2}$ is a promising candidate as highly active cathode material of lithium ion rechargeable batteries. The crystalline-layered lithium cobaltite has attracted increased attention due to recent discoveries of some extraordinary properties such as unconventional transport and magnetic properties. Due to layered crystal structure, $\mathrm{Li}$ contents $(x)$ in $\mathrm{Li}_{x} \mathrm{CoO}_{2}$ might play an important role on its interesting properties. $\mathrm{LiCoO}_{2}$ crystalline cathode material was prepared by using solid-state reaction synthesis, and then $\mathrm{Li}_{\mathrm{x}} \mathrm{CoO}_{2}(x<1)$ has been synthesized by deintercalation of produced single-phase powders. Structure and morphology of the synthesized powders were investigated by $\mathrm{X}$-ray diffraction (XRD), Infrared spectroscopy, Impedance analyzer etc. The influence of lithium composition $(x)$ on structural, electronic and optical properties of lithium cobaltite was studied. Temperature dependent electrical resistivity was measured using four-probe technique. While $\mathrm{Li}_{\mathrm{x}} \mathrm{CoO}_{2}$ with $x=0.9$ is a semiconductor, the highly Li-deficient phase $(0.75 \geq x \geq 0.5)$ exhibits metallic conductivity. The ionic conductivity of $\mathrm{Li}_{\mathrm{x}} \mathrm{CoO}_{2}(x=0.5-$ 1.15 ) was measured using impedance spectroscopy and maximum conductivity of $\mathrm{Li}_{0.5} \mathrm{CoO}_{2}$ was found to be $6.5 \times 10^{-6} \mathrm{~S} / \mathrm{cm}$ at $273 \mathrm{~K}$. The properties that are important for applications, such as ionic conductivity, charge capacity, and optical absorption are observed to increase with Li deficiency.
\end{abstract}

Keywords: Calcination; Characterization; Inorganic compounds; Solid-State reaction; X-ray diffraction.

(C) 2014 JSR Publications. ISSN: 2070-0237 (Print); 2070-0245 (Online). All rights reserved.

doi: http://dx.doi.org/10.3329/jsr.v6i2.17900 J. Sci. Res. 6 (2), 217-231 (2014)

\section{Introduction}

Recently, lithium-ion rechargeable batteries have been much studied for use as a power source of electric vehicles and various portable electronic devices because of their high power and high discharge voltages [1]. Now-a-days, one of the most promising power

\footnotetext{
*Corresponding author: razzaque_ru2000@yahoo.com
} 
sources is the rechargeable lithium ion battery (LIB). High performance LLBs are favored in applications where low weight and small volume is desired, such as laptop computer, cellular phones and various portable electric appliances [2]. All solid-state LIBs using solid-inorganic materials have attracted attention owing to their safely and stability. Performance of the rechargeable batteries are determined by properties of the materials applied for their construction. In case of LIBs the most sensitive part of the device is cathode that may be formed of lithium with transition metal oxides [3]. Materials for cathodes in rechargeable LIBs have known a renewed research interest in recent years, both from the experimental and the theoretical point of view [4-6].

Lithium based layered transition metal oxides $\mathrm{LiMO}_{2}(\mathrm{M}=\mathrm{Ni}, \mathrm{Co}, \mathrm{Mn}, \mathrm{Al}, \mathrm{V})$ have attracted great interest worldwide and most studied for demand of high capacity energy storage devices. These materials are mainly used in lithium ion rechargeable batteries due to their attractive properties such as high energy density, high average output voltage, exceptional cycling behavior, high rate capability and wide working temperature ranges. Among this group, $\mathrm{LiCoO}_{2}$ is one of the most promising materials for commercial application because of its favorable features such as good capacity, excellent electrochemical stability, good power rates, low self-discharge, and excellent life cycle [7]. The structural stability of the $\mathrm{LiCoO}_{2}$ cathode material is such that the layered cation ordering extremely preserved even after a repeated process of insertion and extraction of $\mathrm{Li}^{+}$ions [8]. This topotactic Li-intercalation mechanism is the basis for the materials application of $\mathrm{LiCoO}_{2}$ as an electrode in a rechargeable battery [9].

$\mathrm{LiCoO}_{2}$ crystals in particular have attracted attention due to their layered structure because $\mathrm{Li}^{+}$ions are easily removed from $\mathrm{LiCoO}_{2}$ structure [7]. This layered crystallographic structure is able to accommodate foreign cations in a reversible way, without drastic change of solid matrix. The excess charge created during battery performance is compensated by electrons provided to or removed from the matrix. This is possible for relatively easy change of valence state of transition metal ion in $\mathrm{LiCoO}_{2}$. The amount of energy stored in the battery depends on the charge $\left(\mathrm{Li}^{+}\right.$ions) in the structure of cathode material [3]. The electronic properties of $\mathrm{Li}_{\mathrm{x}} \mathrm{CoO}_{2}$ are sensitively influenced by the $\mathrm{Li}$ content $(x)$ [10]. For a long Li non-stoichiometry range, $\mathrm{Li}_{\mathrm{x}} \mathrm{CoO}_{2}$ would display a mixed electronic/ionic $\left(\mathrm{Li}^{+}\right)$conductivity, consistent with the requirements of electrochemical cathode material. Until now, some interesting structural and electronic properties of this important cathode material are open questions. We want to realize more and more into the structural and electronic and optical properties of $\mathrm{Li}_{\mathrm{x}} \mathrm{CoO}_{2}$.

Properties of $\mathrm{LiCoO}_{2}$ are depends on the conditions of synthesis and subsequent processing. Many methods have been applied for preparation of $\mathrm{LiCoO}_{2}$ crystals such as hydrothermal growth, sol-gel, co-precipitation, pulsed laser deposition, electrostatic spray deposition and solid-state synthesis methods. However, these methods except solid-state reaction route require different difficult conditions or large quantity of solvent and organic materials [11]. There are several disadvantages in hydrothermal growth technique such as expensive equipment and high total cost. For sol-gel crystallization, the grown $\mathrm{LiCoO}_{2}$ crystals have a poor crystallinity [7]. Currently, $\mathrm{LiCoO}_{2}$ has often been synthesized by conventional high temperature solid-state reaction route in factories because this is the most convenient method [12]. In our study, $\mathrm{LiCoO}_{2}$ of high activity as cathode materials 
with high purity and crystallinity have been prepared by solid-state reaction technique.

In this work, we discuss the effects of lithium non-stoichiometry on the structural, electronic and optical properties of $\mathrm{Li}_{\mathrm{x}} \mathrm{CoO}_{2}$. The efficiency of this material as cathode depends on grain size, dislocation density and micro strain. The performance of this cathode material also depends on electrical and ionic conductivity at ambient and high temperature. Studies on the conductivity of delithiated $\mathrm{LiCoO}_{2}$ cathode materials are important to achieve improvement on the ionic conduction mechanism especially in its usage for lithium ion batteries. We showed the change of such conduction properties with Li non-stoichiometry. Further we investigated the variation of charge capacity, dielectric constant, electrical impedance and optical absorption with $\mathrm{Li}$ contents in $\mathrm{Li}_{x} \mathrm{CoO}_{2}$.

\section{Experiment}

High-purity (>99.99\%) powders of $\mathrm{Li}_{2} \mathrm{CO}_{3}$ and $\mathrm{Co}_{3} \mathrm{O}_{4}$ were used as the starting material for preparation of $\mathrm{LiCoO}_{2}$. Initially we studied the phase formation employing a thermobalance (TG/DTA 630) in order to establish the procedure for synthesizing $\mathrm{Li}_{\mathrm{x}} \mathrm{CoO}_{2}$. A stoichiometric mixture of $\mathrm{Li}_{2} \mathrm{CoO}_{3}$ and $\mathrm{Co}_{3} \mathrm{O}_{4}$ with molar ratio of $\mathrm{Li}: \mathrm{Co}=1: 1$ i.e. $x=1.0$, was heated in an air atmosphere with a heating program as shown in the inset of Fig. 1. A representative thermogravimetric (TG) curve obtained for the raw material mixture is shown in Fig. 1. From this thermal analysis, it was found that the weight loss between 500 and $790{ }^{\circ} \mathrm{C}$ is too large due to decarbonation of raw materials followed by the equation $\mathrm{Li}_{2} \mathrm{CoO}_{2} \rightarrow \mathrm{Li}_{2} \mathrm{O}+\mathrm{CO}_{2}$. Endothermic peak at around $710{ }^{\circ} \mathrm{C}$ in differential thermal analysis (DTA) curve indicates the decomposition of $\mathrm{Li}_{2} \mathrm{CO}_{3}$ and exothermic peak at around $790{ }^{\circ} \mathrm{C}$ indicates the formation of $\mathrm{LiCoO}_{2}$ as a result of reaction between $\mathrm{Li}_{2} \mathrm{O}$ and $\mathrm{Co}_{3} \mathrm{O}_{4}$. This suggest that at temperature lower than $\sim 500{ }^{\circ} \mathrm{C}$, the chemical reaction between the raw materials may not be active yet and there is no weight change above $790{ }^{\circ} \mathrm{C}$ where the phase formation is completed.

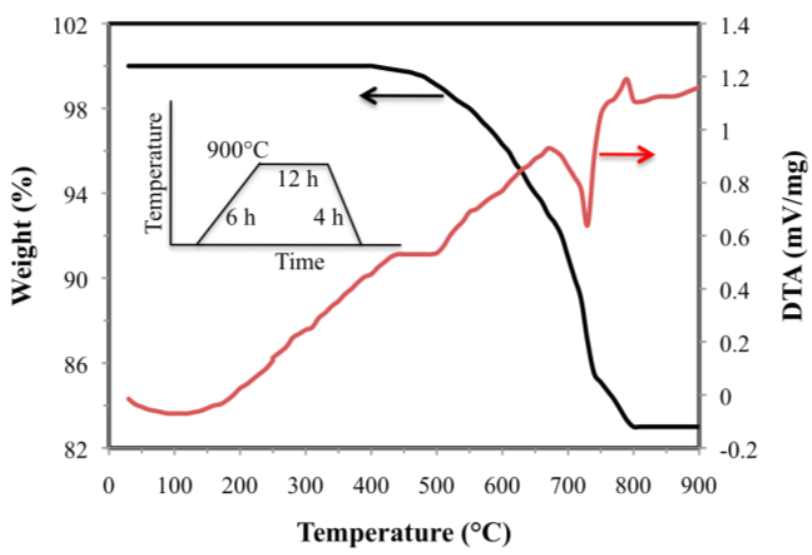

Fig. 1. Thermogravimetric curve for the phase formation process of $\mathrm{LiCoO}_{2}$. The inset represents the heating program employed. 
At the first step of synthesis, the reactants were dried in air in an oven at $100{ }^{\circ} \mathrm{C}$ for 12 h. A powdered mixture of $\mathrm{Li}_{2} \mathrm{CO}_{3}$ and $\mathrm{Co}_{3} \mathrm{O}_{4}$ with molar ratio of $\mathrm{Li}: \mathrm{Co}=1.1: 1$ i.e, $x=1.1$, was mixed well in an agate mortar using ethanol, than dried and calcined at $800{ }^{\circ} \mathrm{C}$ for 24 $\mathrm{h}$ in an air atmosphere. A $10 \%$ molar excess of $\mathrm{Li}_{2} \mathrm{CO}_{3}(x=1.1)$ was added in the mixture to compensate loss due to $\mathrm{Li}$ evaporation at high temperature. Before the next heat treatment, the powder was reground thoroughly to ensure homogeneity. The powder was calcined again at $850^{\circ} \mathrm{C}$ for $12 \mathrm{~h}$ in an air atmosphere. After second heat treatment, the powder was grounded and pelletized in $12 \mathrm{~mm}$ diameter under pressure of $60 \mathrm{KN}$ using pressure gauze. The compressed pellets were sintered at $950^{\circ} \mathrm{C}$ for $12 \mathrm{~h}$ in an air atmosphere. In all heat treatments, the temperature rising and cooling rates were $3{ }^{\circ} \mathrm{C} / \mathrm{min}$. $\mathrm{Li}$ rich composition $\mathrm{Li}_{1.05} \mathrm{CoO}_{2}$ and $\mathrm{Li}_{1.15} \mathrm{CoO}_{2}$ were prepared in the same way of stoichiometric $\mathrm{LiCoO}_{2}$ sample. For preparation of $\mathrm{Li}$ deficient composition $\mathrm{Li}_{\mathrm{x}} \mathrm{CoO}_{2}(0.5$ $\geq x \geq 1.0$ ), the stoichiometric powder, $\mathrm{LiCoO}_{2}$ was deintercalated using mixture of liquid $\mathrm{Br}_{2}$ and acetonytrile. In the deintercalation process, $10 \mathrm{~g}$ samples of stoichiometric $\mathrm{LiCoO}_{2}$ were reacted with different amounts of liquid $\mathrm{Br}_{2}$ according to the relation $x=$ $0.441+0.846 /(R+1.454), R$ is the molar ratio of $\mathrm{Br}_{2}$ to $\mathrm{LiCoO}_{2}$, and $x$ is the lithium content of the deintercalated compound. This equation was derived from ICP-AES analysis of $\mathrm{LiCoO}_{2}$ synthesized by Hertz et al. [13]. The lithium composition was analyzed by using atomic absorption spectroscopy.

The powder samples were analyzed by X-ray diffraction (XRD) using a $\operatorname{CuK}_{\alpha}(\lambda=$ $0.154 \mathrm{~nm}$ ) radiation source using a Rigaku HYGD Multiflex X-ray diffractometer at room temperature in center for crystal science and technology, Japan. The diffraction angle $(2 \theta)$ range between $5^{\circ}$ and $85^{\circ}$ was scanned. Fourier transform infrared (FTIR) spectrophotometer (Spectrum 100, Perkin Elmer) was used for FTIR transmission spectrum of the powder samples. Resistivity measurements were carried out by the conventional four-probe method. Fine polishing was done for the disc like samples. The Agilent Precision Impedance Analyzer (Agilent technologies, Model: 4294A Japan) was used for measurements of frequency dependences ac conductance, impedance, dielectric constant and capacitance. The ionic conductivity was calculated from the complex impedance using Nyquist plot. The samples were characterized by UV-Visible spectrophotometer (Shimazu: UV-1650 PC) for wavelength dependence absorption spectrum.

\section{Results and discussions}

\subsection{Structural properties}

Crystalline $\mathrm{LiCoO}_{2}$ powder was obtained by conventional solid-state reaction technique with a final firing at $850{ }^{\circ} \mathrm{C}$. The powder samples of $\mathrm{Li}_{x} \mathrm{CoO}_{2}$ with $x=0.5-1.15$ were characterized at the room temperature by a Rigaku Mutiflex diffractometer range from $2 \theta=5^{\circ}$ to $85^{\circ}$ with $\mathrm{CuK}_{\alpha}$ radiation $(\lambda=1.5418 \AA)$, at $40 \mathrm{KV}$ and $30 \mathrm{~mA}$. The unit cell refinement was accomplished using XRD data and CellCal software. Typical XRD 
patterns of $\mathrm{Li}_{\mathrm{x}} \mathrm{CoO}_{2}$ crystalline powders shown in Fig. 2 reveals that all these materials are single phase with trigonal crystal structure of hexagonal symmetry, space group $\mathrm{R} 3 \mathrm{~m}$. The

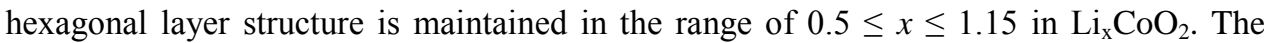
prepared samples were identified as highly crystalline and homogeneous by indexing these XRD patterns using JCPDS data No. 44-0145. Here the sharp peaks indicate the good crystallinity. In the XRD pattern the impurity phase peaks of $\mathrm{Co}_{3} \mathrm{O}_{4}$ and $\mathrm{Li}_{2} \mathrm{CoO}_{3}$ are negligible, so the pure phase solid is obtained, which indicates that $\mathrm{LiCoO}_{2}$ can be synthesized fast by conventional solid-state reaction route. The good crystallinity of $\mathrm{LiCoO}_{2}$ crystals would improve the rate capability of Li-ion cells.

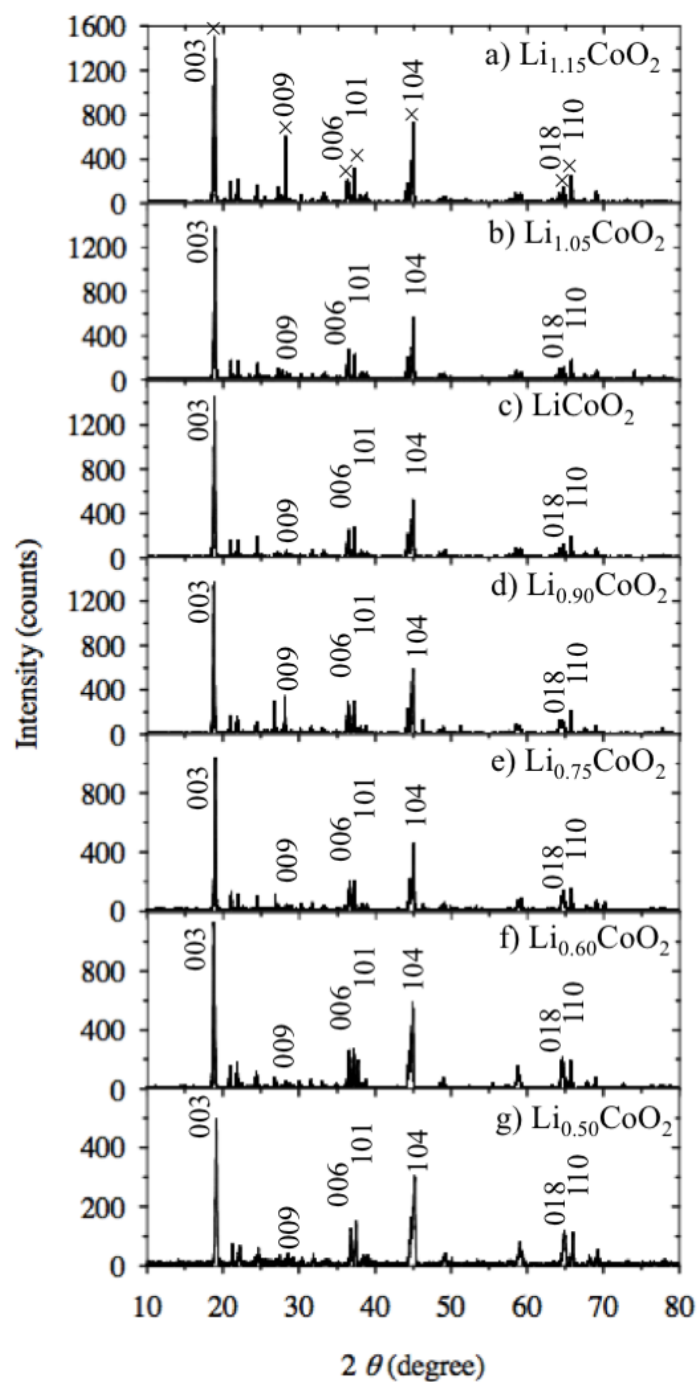

Fig. 2. X-ray diffraction patterns of the $\mathrm{Li}_{x} \mathrm{CoO}_{2}$ samples $(x=0.5-1.15)$. 
In the XRD patterns, (003) peaks indicates the property of layer structure of $\mathrm{LiCoO}_{2}$, (104) peaks indicates the property of basic unit of Co-O-Co bond which form this kind of layer compound, and the intensity ratio of (003) and (104) peaks indicates the perfection of crystallization [12]. The larger value of intensity ratio demonstrates the better crystallinity [14]. The relative intensity of main peaks decreases with increase or decrease of $x$ value in $\mathrm{Li}_{\mathrm{x}} \mathrm{CoO}_{2}$. The table 1 lists the lattice parameters obtained from indexing of XRD pattern using CellCal program and corresponding intensity ratios of main peaks.

Table 1. Lattice parameters derived from X-ray diffraction data and ratio of main XRD peaks.

\begin{tabular}{ccccc}
\hline$x$ in $\mathrm{Li}_{\mathrm{x}} \mathrm{CoO}_{2}$ & $a(\AA)$ & $c(\AA)$ & $c / a$ & $I_{003} / I_{104}$ \\
\hline 1.15 & 2.8258 & 14.1667 & 5.013273 & 2.068 \\
1.05 & 2.8389 & 14.2559 & 5.021462 & 2.479 \\
1.00 & 2.8332 & 14.2476 & 5.028691 & 2.788 \\
0.90 & 2.8359 & 14.3161 & 5.048725 & 2.314 \\
0.75 & 2.8345 & 14.3577 & 5.065323 & 2.275 \\
0.60 & 2.8321 & 14.3603 & 5.070623 & 1.929 \\
0.50 & 2.8378 & 14.3899 & 5.070815 & 1.631 \\
\hline
\end{tabular}

The calculated lattice parameters are approximately equal to the standard lattice constants obtained from the JCPDS card no. 44-0145. The layer structure of $\mathrm{LiCoO}_{2}$ is shown in Fig. 3. The lattice parameter ' $c$ ' increases with reduction of $\mathrm{Li}$ contents $(x)$ in $\mathrm{Li}_{\mathrm{x}} \mathrm{CoO}_{2}$ while lattice parameter ' $a$ ' shows opposite variation. This is consistent with the removal of lithium from $\mathrm{LiCoO}_{2}$, which leads to an increase of the spacing between layers due to repulsive forces between negatively charged oxygen ions [15]. Consequently, this results in expansion of the structure in the direction parallel to the $\mathrm{c}$ axis [16].

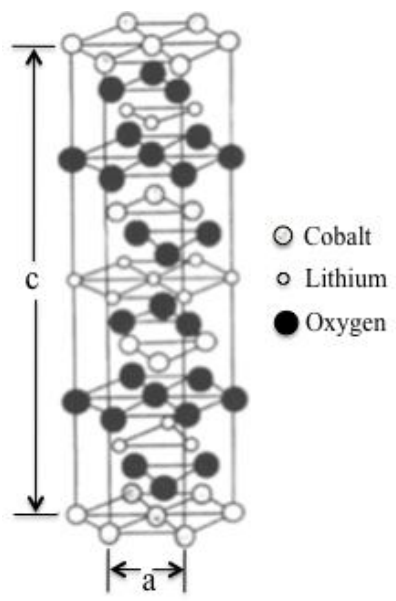

Fig. 3. Crystallographic stricture of trigonal elementary cell of $\mathrm{LiCoO}_{2}$ ( $\mathrm{R} 3 \mathrm{~m}$ space group, hexagonal symmetry). 


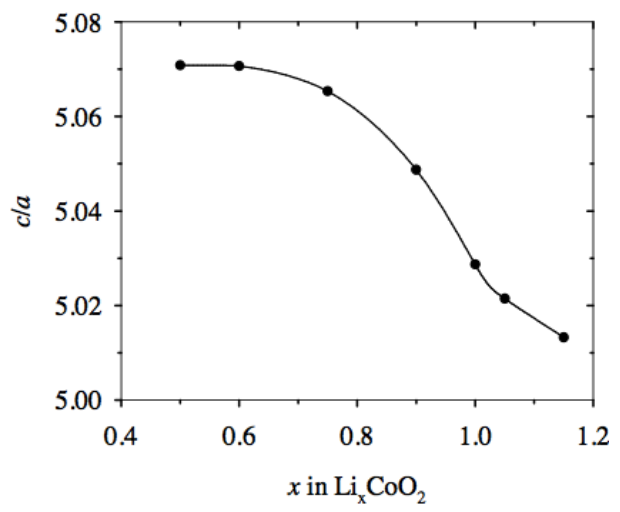

Fig. 4. Variation of the lattice parameter ratio $c / a$ with $x$ value in $\mathrm{Li}_{x} \mathrm{CoO}_{2}$.

The observed slight decrease in lattice parameter ' $a$ ' can be explained by the oxidation of the $\mathrm{Co}^{3+}$ ions and formation of $\mathrm{Co}^{4+}$ ions. The lattice parameter ratio c/a increases with decrease of Li contents $(x)$ as shown in the Fig. 4. As the distance between two $\mathrm{CoO}_{2}$ layers is indicated by the value of $c / a$, this also expresses the expansion of unit cell along c direction. The larger value of $c / a$ implies the structure to be more flexible to deintercalation/intercalation of $\mathrm{Li}^{+}$from $\mathrm{LiCoO}_{2}$ [17].

The cation ordering in the crystal structure of cathode material is one of the most important factors for good performance that is measured by the intensity ratio of main peaks in the XRD patterns. Integrated intensity ratio of (003)/(104) peaks has been considered to be an important factor indicating the degree of cation ordering in the crystal structure of lithium cobalt oxides $[18,19]$. It has been proposed that the electrochemical performance of $\mathrm{Li}_{\mathrm{x}} \mathrm{CoO}_{2}$ cathode material is remarkably improved when the $(003) /(104)$ peaks intensity ratio is higher than 1.2 [20-22]. The intensity ratios of main peaks are shown in Table1 that were more than 1.6 for all values of $x$ in $\mathrm{Li}_{\mathrm{x}} \mathrm{CoO}_{2}$. This reveals that the ordering of $\mathrm{Li}$ and $\mathrm{Co}$ is remain unchanged during the $\mathrm{Li}$ extraction from the sample. On the other hand, the intensity ratio between (003) and (104) reflections decrease significantly due to $\mathrm{Li}$ extraction. This suggests that the cobalt ions present in the $\mathrm{Li}$ planes are extracted along with Li during the oxidation reaction. All diffraction patterns show that the (006) - (101) and (108) - (110) peak doublets are well defined and separated. This suggests a dimensionally stable structure with a highly ordered distribution of cations in the lattice [23, 24].

The performance of the lithium ion battery is affected by a numerous factors such as anode and cathode particle size $(D)$, micro strain $(\varepsilon)$ and dislocation density $(\delta)$ [25]. The average grain size $(D)$ and micro strain $(\varepsilon)$ of the $\mathrm{Li}_{\mathrm{x}} \mathrm{CoO}_{2}$ particles were calculated using Scherrer formulae, $D=\frac{0.94 \lambda}{\beta \cos \theta}$ [26] and $\varepsilon=\frac{\beta}{4 \tan \theta}$ [27], respectively, where $\lambda$ is the X-ray wave length (1.5418 $\AA$ ), 0.94 is the crystal shape constant, $\theta$ is the reflection angle of the highest peak and $\beta$ is the full width at half maximum (FWHM) of the highest peak in radians. The dislocation density $(\delta)$ of the $\mathrm{Li}_{\mathrm{x}} \mathrm{CoO}_{2}$ was estimated using the equation 
$\delta=\frac{1}{D^{2}}\left(\right.$ lines $\left./ \mathrm{m}^{2}\right)$ [28]. The calculated $\mathrm{D}, \delta$ and $\varepsilon$ values are listed in Table 2.

Table 2. Grain size, defect density and micro strain derived from X-ray diffraction data.

\begin{tabular}{cccc}
\hline$x$ in $\mathrm{Li}_{\mathrm{x}} \mathrm{CoO}_{2}$ & $D(\mathrm{~nm})$ & $\delta \times 10^{14}\left(\right.$ lines $\left./ \mathrm{m}^{2}\right)$ & $\varepsilon \times 10^{-3}\left(\right.$ lines.m $\left.{ }^{-4}\right)$ \\
\hline 1.15 & 50.956 & 3.851 & 4.346 \\
1.05 & 45.676 & 4.793 & 4.823 \\
1.00 & 50.261 & 3.957 & 4.390 \\
0.90 & 52.159 & 3.676 & 4.241 \\
0.75 & 61.119 & 2.677 & 3.589 \\
0.60 & 45.867 & 4.753 & 4.836 \\
0.50 & 41.559 & 5.789 & 5.243 \\
\hline
\end{tabular}

The obtained values are comparable to the reported results ofS/cm Yilmaz et al. [25]. The dislocation density $(\delta)$ indicates the length of dislocation lines per unit volume and measures the amount of defects in a crystal. The values of $D, \delta$ and $\varepsilon$ decrease with decrease of $\mathrm{Li}$ content $(x)$ in the $\mathrm{Li}_{\mathrm{x}} \mathrm{CoO}_{2}$ although there is some discontinuity. It means the quality of the lithium cobaltite cathode material improved for delithiation effect.

In order to get physical insight of the chemical bonding and phase formation, we also studied the structure by Fourier transform infrared (FTIR) spectroscopy. FTIR spectroscopic technique is powerful for investigating the local structure and cation environment in oxides [29, 30]. The results of FTIR spectroscopic analysis are shown in the Fig. 5. The main spectrum of $\mathrm{LiCoO}_{2}$ contains the following main absorption bands: 227, 515, 626, 1024, 1384, 1633 and $3435 \mathrm{~cm}^{-1}$. These results confirm the XRD observations showing that the vibration bands for precursors vanished and the vibration bands for the oxide network developed.

In the far-infrared region, we observed the single well-resolved band at $227 \mathrm{~cm}^{-1}$. This sharp band in $\mathrm{LiCoO}_{2}$ is assigned due to an asymmetric stretching motion of the $\mathrm{LiO}_{6}$ octahedra [31]. It is the unique finger print of the Li site occupancy in the trigonal structure. From the spectra shown in the Fig. 5 it is clear that (i) extracting Li ions does not change the space group, (ii) the frequency of the $\mathrm{LiO}_{6}$ octahedra is affected by lithium deintercalation, and (iii) the displacement of the stretching peaks occurs. The slight frequency shift of $\mathrm{LiO}_{6}$ vibrations $\left(227 \mathrm{~cm}^{-1}\right.$ to $\left.225 \mathrm{~cm}^{-1}\right)$ implies that the octahedral oxygen environment of $\mathrm{Li}+$ ions remains quite stable in the delithiated structure.

The strength of $\mathrm{LiO}_{6}$ peaks increase upon Li extraction due to density of oscillators. The broadening of all IR bands is associated with the disorder induced by the departure of the $\mathrm{Li}$ ions located between two $\mathrm{CoO}_{2}$ blocks. The broadening of the low frequency band is also attributed to the random distribution of $\mathrm{Li}$ ions remaining in the host matrix. $\mathrm{A}$ 
slight frequency shift is observed for the high-wave number bands which are assigned to the $\mathrm{CoO}_{6}$ vibrations. This also corresponds to the repulsive interactions between the two adjacent negatively charged $\mathrm{CoO}_{2}$ layers upon deintrcalation. Thus we can conclude that the $\mathrm{CoO}_{2}$ layers are not strongly affected by the lithium deintercalation process. The increase of the absorbance of the $\mathrm{Li}_{\mathrm{x}} \mathrm{CoO}_{2}$ sample can be attributed to the change in the electrical conductivity of the material. This suggests the existence of collective delocalized electrons. These results agree well with the data of electrical measurements, which show that $\mathrm{LiCoO}_{2}$ has a semiconductor like conductivity and $\mathrm{Li}_{\mathrm{x}} \mathrm{CoO}_{2}$ exhibits almost temperature dependent conductivity. There is a sharp medium absorption peaks around $1384 \mathrm{~cm}^{-1}$, which is due to the vibrations of the lithium cobaltite crystal lattice. The results of FTIR analysis were good agreement with XRD results.
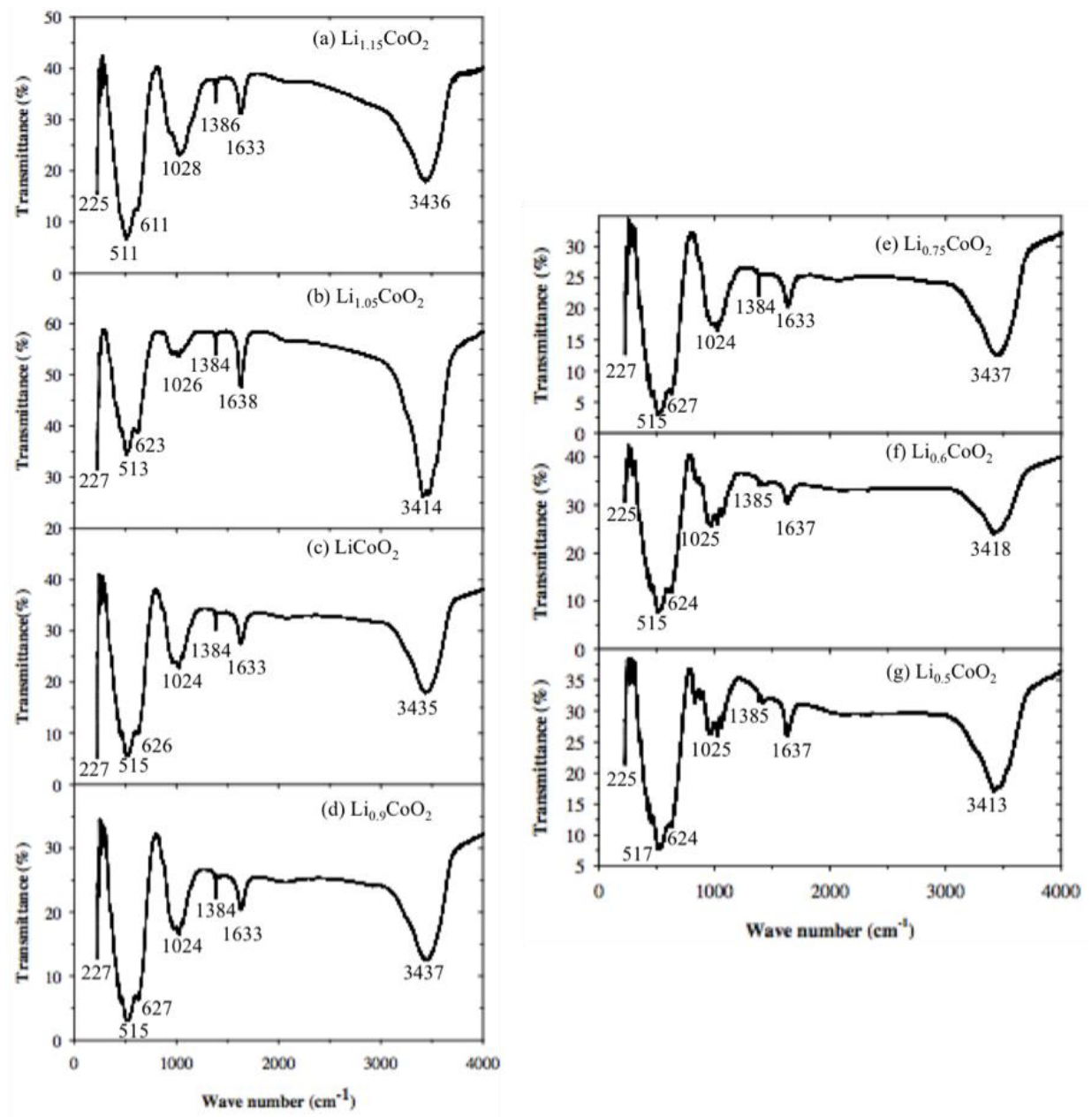

Fig. 5. FTIR spectrum of $\mathrm{Li}_{x} \mathrm{CoO}_{2}$ samples $(x=0.5-1.15)$. 


\subsection{Electronic properties}

The most important property of the electrode material $\mathrm{LiCoO}_{2}$ is its ability to change stoichiometry and, specially, its lithium content within the same structure. The electrochemical change of non-stoichiometry may be expressed by the equation: $\mathrm{LiCoO}_{2} \leftrightarrow$ $\mathrm{Li}_{\mathrm{x}} \mathrm{CoO}_{2}+(1-x) \mathrm{Li}$, where $\mathrm{Li}_{\mathrm{x}} \mathrm{CoO}_{2}$ is lithium deficient composition, forming cathode, and $(1-x) \mathrm{Li}$ represents the amount of lithium that is transferred to anode. In the commercial batteries, the lithium content $x$ in $\mathrm{Li}_{x} \mathrm{CoO}_{2}$ varies between 1 and 0.5 . In this range the structure of $\mathrm{LiCoO}_{2}$ remains unchanged and the battery's performance is reversible [32]. From this point of view, the electrical conductivity of lithium cobaltite may depends on the Li non stoichiometry i.e. lithium content $x$ [29]. In this work we showed the variation of electrical resistivity with $x(x=0.5-1.15)$ in $\mathrm{Li}_{\mathrm{x}} \mathrm{CoO}_{2}$.

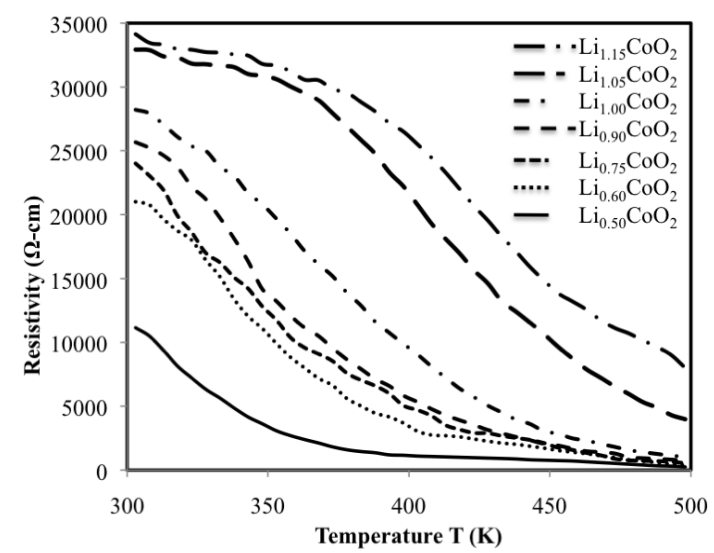

Fig. 6. Temperature dependence electrical resistivity of $\mathrm{Li}_{x} \mathrm{CoO}_{2}$ samples $(x=0.5-1.15)$.

The temperature dependence dc resistivity of the samples was measured using fourprobe technique from room temperature to $500 \mathrm{~K}$ as shown in Fig.6. The electrical resistivity decreases with decreasing $\mathrm{Li}$ content $(x)$ in $\mathrm{Li}_{\mathrm{x}} \mathrm{CoO}_{2}$ which indicates that the electrical conductivity increases for delithiation effect. The results reveal that the resistivity of $\mathrm{LiCoO}_{2}$ is three times larger than that of $\mathrm{Li}_{0.5} \mathrm{CoO}_{2}$. It indicates that $\mathrm{Li}_{\mathrm{x}} \mathrm{CoO}_{2}$ $(x>0.5)$ are semiconductors whereas $\mathrm{Li}_{0.5} \mathrm{CoO}_{2}$ is a metallic semiconductor. The $\mathrm{dc}$ resistivity strongly depends on the temperature. The ac conductance of the samples were measured by impedance analyzer, where the signal frequency was varied from $100 \mathrm{kHz}$ to $10 \mathrm{M} \mathrm{Hz}$ and oscillating voltage $300 \mathrm{mV}$ was applied. Fig. 7 shows the frequency dependence ac conductance of $\mathrm{Li}_{x} \mathrm{CoO}_{2}$ samples where the ac conductance increases with frequency for all the samples. The frequency response ac conductance also depends on the $\mathrm{Li}$ nonstoichiometry of $\mathrm{Li}_{x} \mathrm{CoO}_{2}$ samples. The ac conductance of stoichiometric $\mathrm{LiCoO}_{2}$ is lower than all non stoichiometric samples. The ac conductance of $\mathrm{Li}_{1.15} \mathrm{CoO}_{2}$ and $\mathrm{Li}_{1.05} \mathrm{CoO}_{2}$ are very close to $\mathrm{LiCoO}_{2}$ while that of Li deficient composition is significantly large. The efficiency of cathode materials of the rechargeable batteries depends on the ac 
conductivity. This result indicates that the $\mathrm{Li}$ non stiochiometry of $\mathrm{Li}_{\mathrm{x}} \mathrm{CoO}_{2}$ strongly affects the efficiency of the Li-ion cells [9].

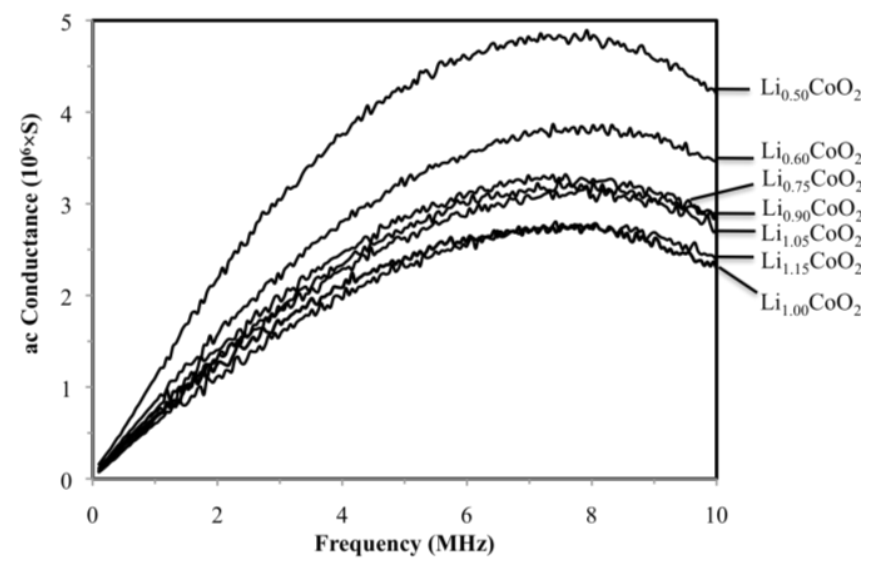

Fig. 7. Frequency dependence ac conductance of $\mathrm{Li}_{x} \mathrm{CoO}_{2}$ samples $(x=0.5-1.15)$.

The ionic conductivity of the samples was calculated by measuring the frequency dependence impedance using precision impedance analyzer. The ionic conductivity could be calculated using the Nyquist impedance plot of imaginary part $\left(Z^{\prime \prime}\right)$ versus real part $\left(Z^{\prime}\right)$ of complex impedance [33]. The complex impedance plot shows a well-defined semicircle in the high frequency region, which is due to bulk effect of the electrodes. The point where the semi-circle tends to intersect the real axis $\left(Z^{\prime}\right)$ gives the value of bulk resistance $R_{\mathrm{b}}$. Inset of Fig. 8 shows the Nyquist complex impedance plot of $\mathrm{Li}_{0.5} \mathrm{CoO}_{2}$ from which the bulk resistance, $R_{\mathrm{b}}$ was obtained directly. By knowing the value of bulk resistance $\left(R_{\mathrm{b}}\right)$ and the dimensions of the sample, the ionic conductivity was calculated by using the relation:

$\sigma=\frac{d}{R_{b} A}$, where $d$ is the thickness and $A$ is the surface area of the sample [34].

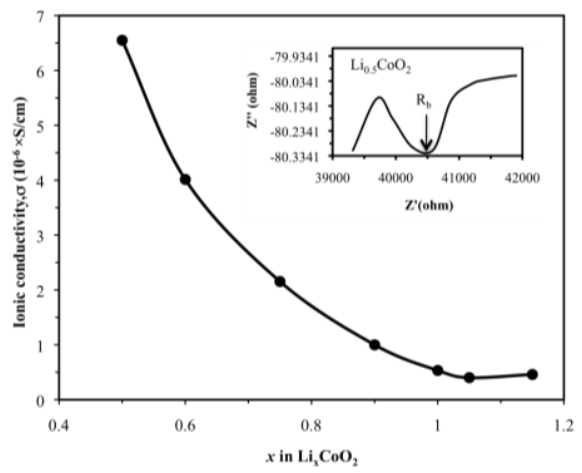

Fig. 8. Ionic conductivity of $\mathrm{Li}_{x} \mathrm{CoO}_{2}$ samples $(x=0.5-1.15)$. 
Fig. 8 shows the ionic conductivity of the $\mathrm{Li}_{\mathrm{x}} \mathrm{CoO}_{2}$ samples for different Li contents $(x)$. The ionic conductivity increased for delithiation effect of $\mathrm{LiCoO}_{2}$ and maximum conductivity of $6.5 \times 10^{-6} \mathrm{~S} / \mathrm{cm}$ was obtained for the composition $\mathrm{Li}_{0.5} \mathrm{CoO}_{2}$. The high ionic conductivity in an electrode is attributed to increased ionic mobility and increased ionic charge carrier concentration.

\subsection{Optical properties}

The optical properties of a material is very important in some applications such as optical coatings, reflectors, absorbers and various optoelectronic devices. The dielectric property of a material is another important factor in electronic device applications.

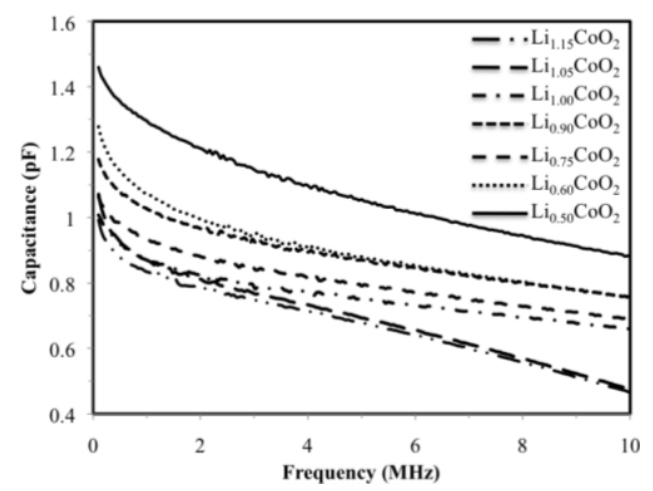

Fig. 9. Frequency dependence capacitance of $\mathrm{Li}_{x} \mathrm{CoO}_{2}$ samples $(x=0.5-1.15)$.

We evaluate the optical and dielectric properties of lithium cobaltite, $\mathrm{Li}_{\mathrm{x}} \mathrm{CoO}_{2}$ as a function of $\mathrm{Li}$ composition $(x)$. Dielectric properties of the $\mathrm{Li}_{x} \mathrm{CoO}_{2}$ samples were measured by precision impedance analyzer. Silver paste was coated on both surface of each sample before measurement. Dielectric constant is a measure of materials ability to store electric charge. The frequency dependence capacitances of samples were measured within the frequency ranges $100 \mathrm{kHz}$ to $10 \mathrm{MHz}$ at room temperature as shown in Fig. 9. The capacitance of $\mathrm{Li}_{\mathrm{x}} \mathrm{CoO}_{2}$ is high at low frequency region and decreases with increase of frequency for all samples. The capacitance of $\mathrm{Li}_{x} \mathrm{CoO}_{2}$ is high at low frequency region due to contribution of all kinds of polarization at low frequency, then decreases with increase of frequency and finally approaches to all most constant value above $12 \mathrm{MHz}$. This is due to the change of space charge, ionic and orientation polarization at higher frequencies [35]. The capacitance of $\mathrm{Li}_{\mathrm{x}} \mathrm{CoO}_{2}$ is lowest for $x=1.15$ and increases with decrease of $x$ value. This means that the charge capacity of the lithium cobaltite cathode increases with decrease of lithium content. Fig. 10 shows the frequency dependence dielectric constant of $\mathrm{Li}_{x} \mathrm{CoO}_{2}$ samples that implies the same tendency of capacitance. Frequency response capacitance and dielectric constant strongly depends on the $\mathrm{Li}$ nonstoichiometry in the $\mathrm{Li}_{x} \mathrm{CoO}_{2}$ samples. 


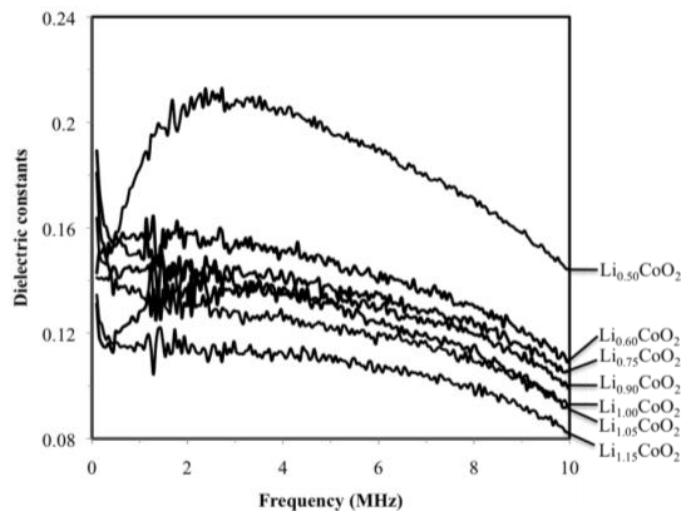

Fig. 10. Frequency dependence dielectric constants of $\mathrm{Li}_{x} \mathrm{CoO}_{2}$ samples $(x=0.5-1.15)$.

The reported results on optical absorption or transmission of bulk $\mathrm{LiCoO}_{2}$ are not available. Rao [36] investigated the optical properties of $\mathrm{LiCoO}_{2}$ thin films using Hitachi U 3400 UV-VIS-NIR double beam spectrophotometer. He recorded the optical absorption spectra in the wavelength range $300-1200 \mathrm{~nm}$ and the absorption peak was found near at $850 \mathrm{~nm}$. In this study, UV-Visible absorption spectrum of the $\mathrm{Li}_{\mathrm{x}} \mathrm{CoO}_{2}$ samples was recorded by using a UV-Vis spectrophotometer (Shimazu: UV-1650 PC) in the photon wavelength range $200-800 \mathrm{~nm}$. Fig.11 shows the absorption spectrum of $\mathrm{Li}_{x} \mathrm{CoO}_{2}$ samples. The absorption slightly increases with increase of wavelength in the visible region. There are some absorption peaks in the ultraviolet region for most of the samples. There are two very strong absorption peaks at $236 \mathrm{~nm}$ and $274 \mathrm{~nm}$ for the $\mathrm{Li}_{0.75} \mathrm{CoO}_{2}$ sample. There are two strong absorption peaks at $208 \mathrm{~nm}$ and $216 \mathrm{~nm}$ and a medium peak at $269 \mathrm{~nm}$ for the $\mathrm{Li}_{0.9} \mathrm{CoO}_{2}$ sample. There are single weak peaks at $201 \mathrm{~nm}$ for $\mathrm{LiCoO}_{2}$, at $203 \mathrm{~nm}$ for $\mathrm{Li}_{0.6} \mathrm{CoO}_{2}$ and at $202 \mathrm{~nm}$ for $\mathrm{Li}_{0.5} \mathrm{CoO}_{2}$ samples. These peaks reveal the absorption criteria of lithium cobaltite in the ultraviolet - visible region depending on the $\mathrm{Li}$ deficiency. There are no peaks observed for $\mathrm{Li}$ rich composition $\mathrm{Li}_{1.05} \mathrm{CoO}_{2}$ and $\mathrm{Li}_{1.15}$ $\mathrm{CoO}_{2}$ in the absorption spectrum. This result reveals that stoichiometric $\mathrm{LiCoO}_{2}$ is not a strong absorber but for delithiation its absorptive power increases. Lithium cobaltite might be used as absorber after deintercalation.

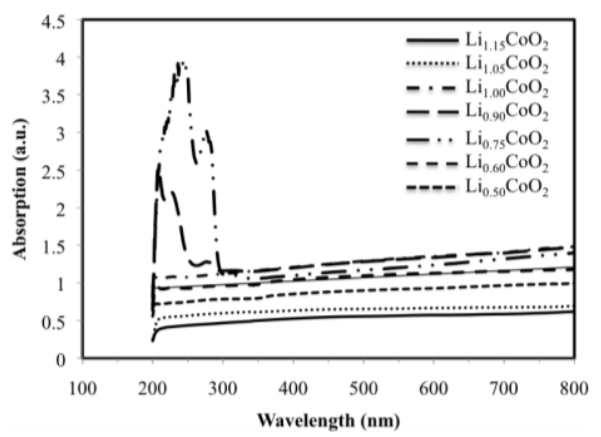

Fig. 11. The UV-Visible absorption spectrum of of $\mathrm{Li}_{x} \mathrm{CoO}_{2}$ samples $(x=0.5-1.15)$. 


\section{Conclution}

Lithium cobaltite $\left(\mathrm{LiCoO}_{2}\right)$ single-phase powders have been successfully prepared by solid-state reaction technique. This technique is most effective to control precisely the $\mathrm{Li}$ contents in the $\mathrm{LiCoO}_{2}$ samples by avoiding unwanted $\mathrm{Li}$ evaporation during synthesis procedure. The $\mathrm{Li}$ deficient compositions $\left(\mathrm{Li}_{\mathrm{x}} \mathrm{CoO}_{2}\right)$ were successfully prepared by deintercalation of $\mathrm{LiCoO}_{2}$ single-phase power. The phase formation condition was fixed by thermal analysis and single crystalline phase was confirmed by XRD analysis. With varying the $\mathrm{Li}$ concentration $(x)$ in the $\mathrm{Li}_{x} \mathrm{CoO}_{2}$ samples, structural, electronic and optical properties were reported first by various experimental techniques. The structural, electrical and optical measurements reveal that its all properties are well agreements with literature. We reported that the crystal of lithium cobaltite remain unchanged upon $\mathrm{Li}$ extraction. The electrical resistivity decreased for delithiation effect and minimum resistivity of $1.1 \times 10^{4} \Omega$-cm was obtained for the composition $\mathrm{Li}_{0.5} \mathrm{CoO}_{2}$. The ionic conductivity enhanced for delithiation effect of $\mathrm{LiCoO}_{2}$ and maximum conductivity of $6.5 \times 10^{-6} \mathrm{~S} / \mathrm{cm}$ was obtained for the composition $\mathrm{Li}_{0.5} \mathrm{CoO}_{2}$. In this article, we evaluated the $\mathrm{Li}$ non stoichiometric effects of $\mathrm{LiCoO}_{2}$ on crystal quality, grain size, micro strain, defect density, charge capacity and optical absorption in first time. We reported that the micro strain and defect density decreased for extraction of $\mathrm{Li}^{+}$from $\mathrm{LiCoO}_{2}$. We also demonstrated that the properties, responsible for high efficiency of $\mathrm{LiCoO}_{2}$ cathode materials, improved for $\mathrm{Li}^{+}$extraction. Further we want to propose here that the performance of $\mathrm{Li}$-ion rechargeable batteries increased for delithiation of $\mathrm{LiCoO}_{2}$ cathode materials.

\section{Acknowledgements}

This work was partially supported by the Rajshahi University Research Grant (No. A 774). The authors would like to thank Mr. Md. Saiful Islam, Senior Scientific Officer, Central Science Laboratory, Rajshahi University, for facilitating experimental works. Further the authors thank Bangladesh Council for Scientific and Industrial Research authority and the Center for Crystal Science and Technology authority for providing experimental facilities.

\section{References}

1. J. M. Tarascon, M. Armand, Nature 414, 359 (2001). http://dx.doi.org/10.1038/35104644

2. C. H. Han, Y. S. Hong, C. M. Park, and K. Kim, J. Power Sources 92, 95 (2001). http://dx.doi.org/10.1016/S0378-7753(00)00505-X

3. T. Bak, J. Nowotny, M. Rekas, C. C. Sorrell, and S. Sugihara, Ionics 6, 92 (200).

4. M. Catti, Phys. Rev. B, 61, 1795 (2000). http://dx.doi.org/10.1103/PhysRevB.61.1795

5. R. Koksbang, J. Barker, H. Shi, and M. Y. Saidi, Solid State Ionics 84,1 (1996). http://dx.doi.org/10.1016/S0167-2738(96)83001-3

6. M. M. Thackeray, J. Electrochem. Soc. 142, 2558 (1995). http://dx.doi.org/10.1149/1.2050053

7. K. Teshima, S. H. Lee, Y. Mizuno, H. Inagaki, M. Hozumi, K. Kohama, K. Yubuta, T. Shishido, and S. Oishi, Cryst. Growth Design 10, 4471 (2010). http://dx.doi.org/10.1021/cg100705d 
8. L. Predoana, A. Barau, M. Zaharescu, H. Vasilchina, N. Velinova, B. Banov, and A. Momchilov Advanced Techniques for $\mathrm{LiCoO}_{2}$ Preparation and Testing, Proceedings of the International Workshop "Advanced Techniques for Energy Sources Investigation and Testing" 4-9 Sept. 2004, Sofia, Bulgaria.

9. M. K. Aydinol, A. F. Kohan, and G. Ceder, Phys. Rev. B, 56,1354 (1997). http://dx.doi.org/10.1103/PhysRevB.56.1354

10. T. Motohashi, Y. Sugimoto, Y. Masubuchi, T. Sasagawa, W. Koshibae, T. Tohyama, H. Yamauchi, and S. Kikkawa, Phys. Rev. B, 83,195128 (2011). http://dx.doi.org/10.1103/PhysRevB.83.195128

11. Q. Dong, N. Kumada, Y. Yonesak, T. Takei, N. Kinomura, J. Ceram. Soc. Japan 119, 538 (2011). http://dx.doi.org/10.2109/jcersj2.119.538

12. H. Guo-rong, L. Gang, P. Zhong-dong, X. Jin, Z. Xin-lon, and Y. Xiao-yuan, J. Cent. South Univ. Technol. 11, 261 (2004). http://dx.doi.org/10.1007/s11771-004-0053-y

13. J. T. Hertz, Q. Huang, T. McQueen, T. Klimczuk, J. W. G. Bos, L. Viciu, and R. J. Cava, Phys. Rev. B 77, 075119 (2008). http://dx.doi.org/10.1103/PhysRevB.77.075119

14. L. Jing, W. Zhaoyin, and W. Meimei, J. Inorg. Materials 17, 1157 (2002).

15. L. P. Gaudart, V. C. Ciomaga, O. Dragos, R. Guillot, and N. Dragoe, J. Cryst. Growth 334,165 (2011). http://dx.doi.org/10.1016/j.jcrysgro.2011.07.024

16. Y. Takahashi, N. Kijima, K. Dokko, M. Nishizawa, I. Uchida, and J. Akimoto, J. Solid State Chem. 180, 31 (2007). http://dx.doi.org/10.1016/j.jssc.2006.09.018

17. Y. H. Wei, H. X. Jie, and C. L. Quan, J. Power Sources 81-82, 637 (1999). http://dx.doi.org/10.1016/S0378-7753(99)00235-9

18. S. S. Mohammad and S. Asgari, J. Nanomater. 8, 2010 (2010).

19. J. R. Dahn, V. von Saken, and C. A. Michal, Solid State Ionics 44, 87 (1990). http://dx.doi.org/10.1016/0167-2738(90)90049-W

20. Y. Hao, Q. Lai, Z. Xu, X. Liu, and X. Ji, Solid State Ionics 176, 1201 (2005). http://dx.doi.org/10.1016/j.ssi.2005.02.010

21. S. Sivaprakash, S. B. Majumder, S. Nieto, and R. S. Katiyar, J. Power Sources 170, 433 (2007). http://dx.doi.org/10.1016/j.jpowsour.2007.04.029

22. S. J. Jin, K. S. Park, M. H. Cho, C. H. Song, A. M. Stephan, and K. S. Nahm, Solid State Ionics 177, 105 (2006). http://dx.doi.org/10.1016/j.ssi.2005.08.015

23. S. A. Needham, G. X. Wang, H. K. Liu, V. A. Drozd, and R. S. Liu, J. Power Sources 174, 828 (2007). http://dx.doi.org/10.1016/j.jpowsour.2007.06.228

24. H. Wang, Y. I. Jang, B. Huang, D. R. Sadoway, and Y. M. Chiang, J. Electrochem. Soc. 146, 473 (1999). http://dx.doi.org/10.1149/1.1391631

25. M. Yilmaz, S. Aydin, G. Turgut, R. Dilber, and M. Ertuğrul, Prog. Nanotech. Nanomater. 1 (1), 5 (2012).

26. M. Yilmaz, G. Turgut, S. Aydin, and M. Ertugrul, J. Chem. Soc. Pak. 34, 283 (2012).

27. K. Rajasekar, L. Kungumadevi, A. Subbarayan, and R. Sathyamoorthy, Ionics 14, 69 (2008). http://dx.doi.org/10.1007/s11581-007-0146-3

28. K. Ravichandran, G. Muruganantham, and B. Sakthivel, Physica B: Condensed Matter 404, 4299 (2009). http://dx.doi.org/10.1016/j.physb.2009.08.017

29. N. Amdoun, P, H. Zarrouk, and C. M. Julienb, Ionics 9, 47 (2003).

30. C. Julien, Solid State Ionics $\mathbf{8 8 7 , 1 3 6}$ (2000).

31. C. Julien, NATO Science Series 309, 3 (2000).

32. M. Menetrier, I. Saadoune, S. Levasseur, and C. Delmas, J. Mater. Chem. 9, 1135 (1999). http://dx.doi.org/10.1039/a900016j

33. X. Qian, N. Gu, Z. Cheng, X. Yan, E. Wang, and S. Dong, J. Solid State Electrochem. 6, 8 (2001). http://dx.doi.org/10.1007/s100080000190

34. A. R. Polu and R. Kumar, Bull. Mater. Sci. 34, 1063 (2011). http://dx.doi.org/10.1007/s12034-011-0132-2

35. W. D. Kingegy, Introduction to Ceramic (John Wilely \& Sons, New York, 1960).

36. M. C. Rao, Int. J. Pure Appl. Phys. 6, 365 (2010). 